\title{
Kant e a Livre Federação das Nações como Meio para a República Mundial
}

\author{
Kant and the free federation of nations as a means to world republic
}

\author{
Joel T. Klein \\ jthklein@yahoo.com.br \\ (Universidade Federal do Paraná, Paraná, Brasil)
}

\begin{abstract}
Resumo: Nesse artigo argumento em favor de duas teses: 1. Que o cosmopolitismo jurídico de Kant envolve uma perspectiva processualista de realização dos ideais normativos, o que se traduz no dever direto de criação de uma livre federação das nações e no dever indireto de estabelecimento de uma república mundial; 2. Que esses deveres jurídicos possuem um caráter distinto no sentido de que eles não implicam a legitimidade de coação. Por fim, avanço algumas reflexões sobre a principais características jurídicas de uma república mundial a partir do modelo de Kant em contraste com outros modelos contemporâneos de herança kantiana.
\end{abstract}

Palavras-chave: Kant; cosmopolitismo; direito; coação; república mundial.

\begin{abstract}
In this paper I defend two theses: 1st. That Kant's juridical cosmopolitanism has a processualist point of view concerning the realization of normative ideals, which implies a direct duty to create a free federation of states and the indirect duty to establish a world republic; 2 nd. That these duties have a distinct juridical character, in the sense that they are not analytically related to coercion. At the end I also advance some reflections on the juridical aspects of the world republic in contrast with other contemporary models that have a Kantian heritage.
\end{abstract}

Keywords: Kant; cosmopolitanism; right; coercion; world republic.

Este artigo está dividido em quatro seções. Na primeira, apresenta-se os elementos centrais do que se pode denominar de cosmopolitismo jurídico de Kant. $\mathrm{Na}$ segunda seção, argumenta-se em favor de uma perspectiva processualista do direito, a qual prevê um dever direto de criação de uma federação das nações e um dever indireto para uma república mundial. Na terceira seção, discute-se o significado de um dever jurídico que não implique um direito de coação imediata, como é o caso do dever jurídico direto de criação de uma federação das nações. Finalmente, na última seção, discutem-se algumas linhas gerais da estrutura normativa de uma república mundial em contraste com as propostas de Höffe e de Habermas.

\footnotetext{
* Bolsista produtividade do CNPq. Essa pesquisa também recebeu apoio de bolsa Pesquisador experiente CAPES/Alexander von Humboldt Stiftung (processo número: 99999.000568/2016-03).
} 
Joel T. Klein

\section{Elementos do cosmopolitismo jurídico}

Kant apresenta sua primeira formulação inequívoca de um cosmopolitismo jurídico no ensaio Idea de uma história universal com um propósito cosmopolita (1784). Trata-se da exigência normativa intrínseca ao conceito de direito acerca da criação de instituições políticas e jurídicas supranacionais cujo objetivo é acabar com o conflito selvagem entre os estados.

O problema de uma constituição civil perfeita depende, por sua vez, de uma relação externa legal entre os Estados e não pode resolver-se sem esta última. (...) A natureza compele os estados (...) a sair do estado sem leis dos selvagens e ingressar numa liga de povos, onde cada Estado, inclusive o mais pequeno, poderia aguardar a sua segurança e o seu direito não do seu próprio poder ou da própria decisão jurídica, mas apenas dessa grande federação de nações (Foedus Amphyctyonum), ${ }^{1}$ de uma potência unificada e da decisão segundo leis da vontade unida [von einer vereinigten Macht und von der Entscheidung nach Gesetzen des vereinigten Willens erwarten könnte] (laG, AA 08: 24). ${ }^{2}$

Nesse excerto, Kant defende a existência de um vínculo conceitual direto entre a possibilidade da justiça em nível estatal com a possibilidade da justiça em nível interestatal. Entretanto, a maneira como ele define essa federação, isto é, com os conceitos de "potência unificada" e de "decisão segundo leis da vontade unida", indica a exigência de uma instituição aos moldes do estado, a qual deveria abranger a totalidade do globo. Nesse sentido, além dos estados, haveria um supra estado, um estado de segunda ordem, que teria

um poder unificado que the dá força; por conseguinte a introduzir um estado civil mundial de pública segurança estatal [einen weltbürgerlichen Zustand der öffentlichen Staatssicherheit], (...) que também não existe sem um princípio da igualdade das ações e reações, a fim de não se destruírem entre si (laG, AA 08: 26).

Kant reconhece que já na sua época os estados se ofereciam como árbitros para mediar conflitos alheios, mas faziam isso sem possuírem qualquer competência jurídica para isso. De todo modo, isso já pode ser visto como a preparação "para um futuro grande corpo político [Staatskörper], de que o mundo precedente não pode ostentar exemplo algum", para que assim seja constituída "uma condição cosmopolita [weltbürgerlicher Zustand] como o seio em que se desenvolverão todas as disposições originárias do gênero humano" (IaG, AA 08:28), ou ainda "um todo

1 “Foedus amphyctyonum" faz referência à coligação das cidades-estados gregas, cuja função era sua mútua proteção (cf. Höffe, 2006, p.170).

2 Todas as citações das obras de Kant seguem os padrões estabelecidos pela Akademie Ausgabe. Nesse sentido, as siglas das obras de Kant utilizadas aqui indicam os seguintes textos: laG = Ideia de uma história universal com um propósito cosmopolita; TP = Sobre a expressão corrente, isso pode ser correto na teoria mas não serve para a prática; $R G V=$ Religião nos limites da simples razão; GMS = Fundamentação da metafísica dos costumes; $\mathrm{KU}=$ Crítica da faculdade do juízo; ZeF = À paz perpétua; MS = Metafísica dos costumes; SF = Conflito das faculdades. 
cosmopolita [weltbürgerliches Ganze]", isto é, um sistema de todos os Estados que correm o risco de atuar entre si de forma prejudicial” (KU, AA 05: 432).

Em Sobre a expressão corrente isso pode ser correto na teoria, mas não serve para a prática (1793), o tema do cosmopolitismo jurídico é retomado. Kant rejeita o pretenso realismo internacional do direito que pretende sustentar a paz no sistema de "equilíbrio de poder". Segundo ele, tal sistema "é como a casa de Swift, que fora construída por um arquiteto de modo tão perfeito, segundo todas as leis do equilíbrio, que imediatamente ruiu quando um pardal em cima dela pousou" (TP, AA 08: 312). A única alternativa restante para uma paz duradoura é então a submissão a uma lei pública, isto é, "ingressar numa constituição cosmopolita [weltbürgerliche Verfassung]" (TP, AA 08: 310f.). Da mesma forma que o estado se apresenta como a instituição necessária para garantir o direito e dar um fim à guerra de todos contra todos no âmbito dos indivíduos, os estados deveriam também dar esse mesmo passo, ou seja, sair do seu estado de natureza no qual "nenhum estado, em relação a outro, se encontra um só instante seguro quanto à sua independência ou propriedade", de modo que "para tal situação nenhum outro remédio é possível a não ser (por analogia com o direito civil ou político de homens singulares) o direito das gentes, fundado em leis públicas apoiadas no poder, às quais cada estado se deveria submeter" (TP, AA 08: 312). Nesse sentido, Kant conclui que o direito recomenda a introduzir-se um tal “estado universal dos povos [allgemeiner Völkerstaat]” TP, AA 08: 313).

Na Religião nos limites da simples razão (1793), Kant nomeia essa "liga de povos como uma república mundial [Völkerbund als Weltrepublik]" (RGV, AA 06: 34). O problema do status e do conteúdo desse cosmopolitismo jurídico parece sofrer uma mudança a partir do ensaio À paz perpétua (1795). Entretanto trata-se apenas de aparência, o que ocorre é o reconhecimento de que somente poderíamos nos aproximar da realização de uma república mundial por meio da criação de uma federação livre de estados. ${ }^{3}$

A exigência de um cosmopolitismo é vinculada na MS diretamente ao próprio conceito de direito. "Age exteriormente de tal maneira que o livre uso do teu arbítrio possa coexistir com a liberdade de qualquer um segundo uma lei universal" (MS, AA 06:231). Essa é a formulação de Kant do imperativo categórico do direito. Nesse sentido, "não posso por meio de um arbítrio unilateral obrigar um outro a se abster do uso de uma coisa para o que ele não teria, aliás, nenhuma obrigação; portanto somente o posso por meio do arbítrio unificado de todos numa posse comum" (MS, AA 06:261). Há, desse modo, um vínculo direto entre a realização do meu direito e o conceito de um estado civil jurídico e uma vontade omnilateral (cf. MS, AA 06: 264). Entretanto é importante ressaltar que esse conceito de omnilateral implica que

3 Discuto essa mudança e as diferentes interpretações que ela produziu ao longo da história em Klein (2020). 
qualquer "aquisição será sempre apenas provisória se esse contrato não se estender a todo o gênero humano" (MS, AA 06:266).

$O$ conceito de estado civil é, portanto, uma exigência do direito. Um elemento dessa realização se refere à autorização para coagir (cf. MS, AA 06: 231). Apenas no estado há uma estrutura em que a capacidade de coação pode ser exercitada segundo as exigências racionais de uma vontade unida, ou seja, apenas no estado é possível falar de justiça distributiva. ${ }^{4}$ Fica evidente que o cosmopolitismo jurídico kantiano se caracteriza como uma vertente jurídica e política que se distingue, assim, da vertente do cosmopolitismo ético defendido na antiguidade (cf. Höffe, 2006, p.14; Nussbaum, 1995).

É exatamente pela falta da existência de instituições estatais jurídicas capazes de garantir força legal ao direito das gentes que Kant atribui a Hugo Grócio, Pufendorf e Vatel o título de “meros tristes consoladores [lauter leidige Tröster]" (ZeF, AA 08: 355). Na Metafísica dos Costumes essa exigência racional é reapresentada na seção sobre o direito das gentes: ${ }^{5}$

Uma vez que o estado de natureza entre os povos, tanto quanto entre os indivíduos, é um estado de que se deve sair para entrar em um estado geral, assim, antes desse acontecimento, todo o direito dos povos e todo o meu e teu externo dos Estados que pode ser adquirido e mantido mediante a guerra são apenas provisórios, podendo valer peremptoriamente e tornar-se um verdadeiro estado de paz tão somente em uma união universal dos Estados (análoga àquela união pela qual um povo se torna um Estado) (MS, AA 06:350).

Em suma, a saída do estado de natureza e a entrada no estado civil pressupõe a abdicação da liberdade selvagem, a qual é definida precisamente por cada um se considerar soberano, intérprete e executor da causa própria, para aquisição da liberdade civil, por conseguinte, de se submeter às leis da vontade unida, ou ainda de uma vontade omnilateral, a qual somente pode ser exercida dentro de um sistema de instituições estatais. Trata-se de uma exigência normativa derivada do próprio conceito de direito e que conduz ao conceito de um modelo estatal de âmbito global.

\section{Dever direto para com uma federação das nações e o dever indireto para com a república mundial}

$\mathrm{Na}$ introdução à Metafísica dos costumes encontra-se uma passagem estruturalmente importante e difícil, na qual ele afirma:

4 Cf. "Toda ação que cause prejuízo ao direito de uma pessoa merece castigo, por intermédio do qual se vingue o delito no autor da ação (não apenas para que se repare o dano causado). Ora, a punição [Strafe] não é um ato de autoridade privada do ofendido, mas de um tribunal distinto dele, que confere eficácia às leis de um superior em relação a todos os que the são submetidos; e se considerarmos os homens num estado jurídico (...) segundo leis racionais" (MS, AA 06:460) Note-se então que a possibilidade de coação jurídica exige uma instituição aos moldes do estado.

5 É importante sempre ter em vista que o conceito de gentes ou povos em Kant possui uma conotação político-jurídica e não genealógica ou antropológica (cf. MS, AA 06: 343). 
podem muito bem estar ligados, num sujeito e na regra que ele se prescreve, dois fundamentos da obrigação (rationis obligandi), sendo um ou outro, no entanto, insuficiente para a obrigação (rationes obligandi non obligantes), quando então um dos dois não é dever. Se dois de tais fundamentos colidem entre si, a filosofia prática não diz que a obrigação mais forte predomina (fortior obligatio vincit), mas que o fundamento de obrigação mais forte domina (fortior obligandi ratio vincit) (MS, AA 06:224).

No contexto do cosmopolitismo legal encontra-se exatamente uma situação de conflito de fundamentos de obrigações. Por um lado, existe a exigência de expandir as relações jurídicas ao âmbito global até a criação de uma república mundial. Por outro lado, há também a exigência de evitar um mal maior, qual seja, a criação de um estado mundial despótico, denominado de monarquia universal. ${ }^{6}$ Nesse contexto de conflito surgem dois resultados: Primeiro, que o fundamento de obrigação mais forte domina a situação, ou seja, torna-se um dever evitar a criação de um estado mundial despótico. Segundo elemento, o fundamento de obrigação que cedeu espaço num primeiro momento, reaparece posteriormente, ${ }^{7}$ ou seja, deve-se construir uma instituição, que não é ainda um estado mundial, por conseguinte, que pode ser somente uma federação livre de estados, a qual, por sua vez, deve gradualmente lançar as bases morais e institucionais para uma república mundial.

É possível reconhecer essa estrutura argumentativa operando implicitamente nas passagens em que Kant trata tanto da federação livre dos estados, quanto da república mundial. Em um primeiro nível Kant afirma que os estados não podem coagir-se mutuamente para entrar em um estado civil mundial, mas devem apenas formar uma aliança:

é necessária uma aliança dos povos segundo uma ideia de um contrato social originário (...) que a aliança não deve, contudo, conter um poder soberano (como

6 Nesse sentido, ver: "por que as leis, com o aumento do âmbito de governação, perdem progressivamente a sua força e também porque um despotismo sem alma acaba por cair na anarquia, depois de ter erradicado os germes do bem" (ZeF, AA 08:367). Na Metafísica dos costumes, lê-se "com a excessiva extensão sobre grandes territórios, seu governo e assim também a proteção de cada um dos membros têm de se tornar finalmente impossíveis, enquanto uma multiplicidade de tais corporações acarreta novamente um estado de guerra" (MS, AA 06:350). Na Religião, "Mas este monstro [a monarquia mundial] (em que as leis perdem, pouco a pouco, a sua força), após ter devorado todos os vizinhos, acaba por dissolver a si próprio e, graças à insurreição e à discórdia, divide-se em muitos estados mais pequenos, os quais, em vez de tender para uma associação de estados (república livre de povos aliados), começam cada um por seu lado o mesmo jogo, para não deixar que cesse a guerra". (RGV, AA 06: 34n.) Nesse sentido, é importante ter em mente que a rejeição de Kant de um estado mundial é a rejeição da monarquia universal e não de uma república mundial (nesse sentido, também McCarthy, 2002; Kleingeld, 2004, 2012; Hruschka/Bird, 2008). Sobre o conceito de monarquia universal, ver: Bosbach (1998).

7 Esse aspecto de que um fundamento de obrigação que perde espaço num primeiro momento pode reaparecer em outra situação já foi indicado por autores como Timmermann (2013) e O'Neill (2002, p.342f.). Entretanto, tais intérpretes restringem sua interpretação apenas para o âmbito ético, ou seja, não o aplicam para o caso do direito. Ora, como tal passagem está na introdução geral da Metafísica dos costumes, ela pode ser interpretada como fazendo também referência ao âmbito do direito. 
Joel T. Klein

uma constituição civil), mas apenas uma confederação (federalismo), uma aliança que pode ser desfeita a qualquer tempo, tendo assim de ser renovada de tempos em tempos - um direito, subsidiário de um outro direito originário, de se defender contra a degeneração em estado de guerra efetiva dos povos entre si (foedus Amphictyionum) (MS, AA 06: 344).

Exatamente com base na exigência normativa de evitar o despotismo global na forma de uma monarquia universal que surge a exigência normativa de criação de uma federação com poder soberano. Em outras palavras, a insistência no aspecto provisório dessa aliança se justifica com relação ao dever de manter afastado o mal maior de um despotismo desalmado ou mesmo de uma queda constante em guerra civil. Nesse sentido, essa aliança não acaba absolutamente com o estado de guerra, mas afasta o mal maior de uma monarquia universal.

Entretanto, ao mesmo tempo em que afasta o mal da monarquia universal, a instituição de uma aliança livre também comporta em si mesma um elemento de iniciar a construção de um direito internacional, ainda que precário e provisório. Após o estabelecimento do dever de evitar a criação de um estado mundial despótico, segue-se um segundo nível, o dever de criar uma federação livre dos estados:

Mas entende-se aqui por congresso apenas uma reunião arbitrária de diversos Estados que pode ser dissolvida em qualquer tempo, e não uma união (como a dos Estados americanos) fundada sobre uma constituição política e, portanto, indissolúvel; somente por tal congresso pode ser realizada a ideia de um futuro direito público dos povos de decidir suas disputas de forma civilizada, como que por um processo, e não de forma bárbara (a maneira dos selvagens), através da guerra (MS, AA 06:351).

Ora, é importante chamar a atenção para o fato de que em nenhum momento dessa formulação Kant rejeita o dever de criação da república mundial. Ao contrário, assevera que a criação de uma federação livre é o meio necessário: "somente por tal congresso pode ser realizada a ideia". ${ }^{8}$ Nesse sentido, de uma perspectiva metafísica e teleológica, a federação das nações pode ser vista como um momento intermediário necessário pelo qual a paz perpétua somente pode ser alcançada com a criação de uma república mundial:

assim a paz perpétua (objetivo último de todo o direito das gentes) é certamente uma ideia inexequível. Mas não assim os princípios políticos que a têm como fim, a saber, os que mandam entrar em alianças dos Estados tais que servem para uma aproximação continuada à paz perpétua; como essa aproximação é uma tarefa fundada no dever, portanto também no direito dos homens e dos Estados, ela certamente é realizável (MS, AA 06:350).

Esse elemento processualista envolve um argumento desenvolvido em dois níveis, o que pressupõe um conflito de fundamento de obrigações que pode ser resolvido a partir de uma perspectiva teleológica. Assim, num primeiro nível, trata-se de afastar

8 Kleingeld (2004, p.307) formula muito bem esse ponto. 
o mal maior, o despotismo de uma monarquia mundial, o que somente pode ser alcançado por um dever de não usar coação na criação de uma federação das nações. Em seguida, num segundo nível, de utilizar essa federação livre das nações para ir gradualmente construindo as bases para uma república mundial, a qual, uma vez criada, implica no direito de usar coação para garantir a paz e fazer valer o direito. Em outras palavras, num primeiro momento, o dever de não usar coação para, num segundo momento, fazer valer o dever de criar a coação.

É nesse sentido que proponho a leitura da controversa passagem da ZeF:

[Primeiro momento] Os estados com relações recíprocas entre si não têm, segundo a razão, outro remédio para sair da situação sem leis, que encerra simplesmente a guerra, senão consentir leis públicas coativas, do mesmo modo que os homens singulares entregam a sua liberdade selvagem (sem leis), e formar um estado de povos [Völkerstaat] (civitas gentium), que (sempre, é claro, em aumento) englobaria por fim todos os povos da terra. [Segundo momento] Mas se, de acordo com a sua ideia do direito das gentes, isto não quiserem, por conseguinte, se rejeitarem in hipothesi o que é correto in thesi, então a torrente da propensão para a injustiça e a inimizade só poderá ser detida, não pela ideia positiva de uma república mundial [Weltrepublik] (se é que tudo não se deve perder), mas pelo sucedâneo negativo [negative Surrogat] de uma federação antagônica a guerra, permanente e em contínua expansão, embora com o perigo constante da sua irrupção (ZeF, AA 08: 357).

Note-se que, aqui, a ordem de apresentação dos fundamentos normativos é reversa. Ou seja, primeiro indica-se o dever de criação de uma república mundial, a qual garantirá o direito de coação recíproca entre os estados, mas, em um segundo momento, por que os estados “não querem" abdicar livremente da sua coação selvagem, por conseguinte, pela ausência de um direito de coação para a criação da república, assume-se então a possibilidade normativa da federação livre como o meio aceitável. A ausência do direito de coação significa aqui a ilegitimidade da coação para a criação da república mundial.

Muitos intérpretes defendem que nessa passagem de ZeF como um erro de Kant no sentido de que ele estaria abdicando de um dever categórico em função de uma questão meramente pragmática, isto é, abdica-se daquilo que a razão exige com base na vontade arbitrária dos estados em não quererem abrir mão de sua liberdade selvagem. Isso indicaria um erro da parte de Kant, pois ele estaria renegando o que ele mesmo havia estabelecido em $T P$, de que uma teoria verdadeira não deve ser abandonada pelo simples fato de que ela não possa ser imediatamente realizada na prática. Isso parece ser indicado pela terminologia do "in thesi" e "in hipothesi", ou ainda, da "ideia positiva" em detrimento do "sucedâneo negativo". Posto de outra forma, a conclusão de Kant do segundo artigo definitivo para a paz perpétua indicaria que razões pragmáticas (de que os estados arbitrariamente não querem abdicar de sua liberdade selvagem) teriam precedência sobre razões morais (dever de abdica da liberdade selvagem), o que é contraditório com algumas das teses mais 
Joel T. Klein

centrais da filosofia prática kantiana.

Sugiro interpretar essa passagem a partir da perspectiva de um conflito de razões de obrigação, que Kant desenvolve na MS. Assim, Kant não estaria abandonando a teoria em detrimento de razões prudenciais ou contingentes, mas estaria contextualizando a sua teoria moral, assim como ocorre no caso da teoria matemática para resolução de um problema concreto da balística, isto é, como necessitando de acréscimo de mais teoria. Nesse caso, essa teoria a ser acrescida envolve a consideração de que em determinados contextos pode haver um conflito de fundamentos de obrigação, os quais podem ser resolvidos a partir de uma reflexão teleológica que permite uma perspectiva e uma solução processualista. Em outras palavras, o conflito de razões de obrigação pode ser apresentado da seguinte forma: de um lado, o dever dos estados de não usarem coação para a criação de uma instituição supra estatal, ou ainda, o dever de evitar uma monarquia universal; de outro lado, o dever dos estados de abandonarem sua liberdade selvagem, o que se realiza de modo mais perfeito em um república mundial. Esse conflito é superado por uma solução que evita o mal maior, mas que, ao mesmo tempo, também pode ser compreendido como um meio para a criação da situação jurídica perfeita. Assim, não se trata de abdicar de um dever moral em detrimento de uma razão pragmática. Ao contrário, trata-se de se utilizar de um raciocínio teleológico ou ainda, consequencialista, no interior da filosofia prática para solucionar uma situação de conflito de razões de obrigação ${ }^{9}$, as quais, por sua vez, se justificam a partir de uma perspectiva deontológica, isto é, a partir do imperativo categórico do direito.

Há, assim, a formulação processual do dever em situações de conflito de razões de obrigação. Da impossibilidade de se realizar perfeitamente o ideal de uma república mundial não se segue um argumento para se rejeitar o mandamento acerca de uma contínua aproximação. Nesse sentido, a criação de uma federação livre é um dever, mas ao mesmo tempo, um estágio necessário para a criação de um estado mundial republicano. Ora, esse mesmo raciocínio se aplica ao âmbito dos estados existentes. Kant reconhece que um perfeito estado republicano jamais existirá na experiência, mas disso não se segue que os estados não deveriam ser criados, ou que estados com governos republicanos, mais ou menos perfeitos, não possam se formar ao longo da história. Mas então, o que exatamente torna a paz perpétua inexequível? Há dois elementos aqui. Primeiro, por definição nunca um ideal ou uma ideia pode ser completamente realizável (cf. SF, AA 07:91). Nesse ponto, alguns intérpretes parecem confundir ou não reconhecer a diferença entre reconhecer a irrealizabilidade completa de uma ideia, como a de uma república mundial, e a perspectiva de uma aproximação constante (ver Muholand, 1987; Raponi, 2008; Baynes, 1997). ${ }^{10}$ Mas

9 Sobre o papel da prudência no contexto da filosofia política e jurídica de Kant ver Klein (2017a). 10 Aqui uma questão de contexto também é relevante. Quanto Kant, em ZeF, AA 08: 371, afirma que 
isso também se aplica a outros campos sem que signifique um argumento para seu abandono, por exemplo, é impossível desenhar um círculo absolutamente perfeito, mas isso não significa que não possamos traçar círculos suficientemente adequados para nossos propósitos. Segundo elemento, o adjetivo "perpétuo" indica algo que não pode ser garantido empiricamente, não enquanto os seres humanos tiverem a atual constituição. Por melhor que sejam as instituições, cada geração precisa estar comprometida não apenas com a manutenção das instituições republicanas, mas também com seu contínuo melhoramento. Ora, não é possível oferecer uma garantia absoluta para isso. Assim, o modo mais adequado de compreender o significado de "à paz perpétua" não é a indicação de uma condição, mas antes de um adjetivo normativo, "uma tarefa" constante, ou ainda, uma tarefa à qual cada geração deve se dedicar. Mas, enquanto tarefa, não se trata mais de algo inexequível. A paz perpétua indica, assim, um referencial para onde todos os esforços humanos no âmbito político jurídico devem ser direcionados, mesmo que eles não alcancem sua realização plena. A paz perpétua se apresenta como o conceito do sumo bem político da razão prática, a qual contém elementos normativos (dever) junto com uma expectativa legítima da possibilidade de uma aproximação continuada cujo estatuto teórico é o de uma esperança prática bem fundada (cf. último parágrafo de ZeF, AA 08: 386).

\section{Direito e coação no âmbito internacional}

O peculiar dos deveres jurídicos e, por conseguinte, do conceito de direito, em contraste com os deveres éticos, se encontra na característica de que os deveres jurídicos se referem primeiro apenas a ações externas e, segundo, permitem outros móbeis além ou independentemente o conceito de dever. Os direitos jurídicos permitem o uso de coação externa, ou seja, os indivíduos podem ser coagidos a cumprirem os seus deveres jurídicos. Como Kant desenvolve de modo emblemático na introdução aos Princípios metafísicos da doutrina do direito: "está ligado ao direito ao mesmo tempo uma autorização de coagir aquele que the causa prejuízo, segundo o princípio de contradição" (MS, AA 06:231; 396). Em outras palavras, é analítico ao conceito de direito a possibilidade de coação, ou ainda, não se pode falar de direito sem que se fale ao mesmo tempo de autorização para a coação.

Ora, mas nesse caso, como se pode falar de um dever jurídico de entrar em uma federação dos estados, a qual é livre, ou seja, não comporta coação? Ou ainda, como se pode falar de um dever de se aproximar de uma república mundial se os estados não têm o direito de se coagirem mutuamente em direção a esse fim? Acerca desse problema há também uma grande divisão na literatura. Por um lado,

a república mundial é um ideal irrealizável, nesse contexto ele está apenas explicitando as teses do moralista político que pretende derivar suas máximas da experiência. 
encontra-se na literatura a posição que afirma que Kant se equivocou e que deveria ter assumido um direito de coação mútua (cf. Axinn, 1989; Carson, 1988) ou ainda, que Kant na verdade assumiu explicitamente (cf. Byrd/Hruscka, 2008, p.624s; 2010, p.195s) ${ }^{11}$ ou implicitamente esse direito (cf. Berstein, 2014, p.245). ${ }^{12}$ Por outro lado, existe um outro grupo de intérpretes que defende que Kant deveria ter aberto mão de uma definição tão estrita de direito, ou seja, que é possível direito sem coação (cf. Merkel, 1996).

Apesar de rejeitar a legitimidade de coação mútua entre os estados para a formação da federação dos povos, Kant continua falando de um dever de abandonar o estado de natureza entre os estados. Nesse caso, cabe investigar se um dos teoremas centrais da filosofia do direito de Kant está equivocado, a saber, se nem todo direito jurídico está relacionado com a faculdade de coação.

Para Kant, "a todo dever corresponde um direito, considerado como uma faculdade (facultas moralis generatim), mas nem a todos os deveres correspondem direitos por parte de outrem a coagir alguém (facultas iuridica); sendo que estes se chamam especificamente deveres jurídicos" (MS, AA 06:383; cf.260). Nessa formulação, fica claro novamente que a todos os deveres jurídicos está associado o direito da parte de outrem a coagir alguém. Entretanto, se analisarmos algumas

11 Byrd e Hruschka sustentam seu ponto com duas citações que se encontram na Doutrina do direito, a saber: "Com aquele direito originário da guerra de Estados livres uns contra os outros no estado de natureza (para talvez fundar um estado que se aproxime do estado jurídico), colocase primeiramente a questão (...)(MS, AA 06: 344, 25-27); e "Aqui é considerado o Estado, como uma pessoa moral, na relação com um outro em estado de liberdade natural e, por conseguinte, de guerra contínua, sendo colocado o problema, em parte, do direito para a guerra, em parte, do direito de obrigar um ao outro [einender zu nöthingen] a sair do estado de guerra, portanto a entrar em uma constituição fundante da paz permanente, i. é, do direito após a guerra. (MS, AA 06: 343, 20-26) Entretanto, essa interpretação das passagens é equivocada, pois ambas as passagens são recortadas do seu contexto tendo seu significado corrompido. Em primeiro lugar, na primeira passagem, a questão da guerra como meio de coação para entrar em um estado jurídico é posta em questão e não afirmada. Isso é indicado pela formulação geral do contexto, que indica um questionamento do uso dos súditos na guerra e não a questão da coação recíproca entre estados para formar uma instituição jurídica (esse ponto também é destacado por Mikalsen, 2011, p.306ss). Em segundo lugar, na segunda passagem, a qual é textualmente anterior, "einender zu nöthingen" não significa necessariamente direito de coação recíproca, mas apenas uma demanda, a legitimidade de exigência moral recíproca, a qual pode ser interpretada como uma demanda moral. Finalmente, em nenhum outro momento do desenvolvimento do texto Kant afirma de modo textual e claro a existência de um direito de coação entre estados para formar uma república mundial, bem pelo contrário, insiste em uma federação livre de estados.

12 Concordo com a resposta de Kleingeld (2014) a Berstein, mas nesse caso, também a Byrd e Hruschka, de que em nenhum lugar Kant menciona explicitamente o direito dos estados de se coagirem mutuamente para entrar em uma federação das nações ou uma república mundial. Kleingeld chama corretamente a atenção para a diferença entre, por um lado, o direito de autodefesa, que Kant traduz como o direito da, na e após a guerra (MS, AA 06:346-350), com, por outro lado, um alegado direito de coação para entrar em um estado jurídico. Falar de uma coação, cuja decisão caberia ao político moral, ou seja, uma coação tal que não fosse realizada com o propósito de conquista ou do espírito de uma monarquia mundial, é ainda altamente problemático e não encontra suporte textual. Sugerir que isso não contradiz o espírito da filosofia de Kant é uma outra tese, mas também é ainda problemática. 
outras distinções, a situação fica mais ambígua.

Proponho aqui a seguinte hipótese interpretativa: que o vínculo analítico entre direito e faculdade de coação se estabelece apenas no contexto do direito civil e do direito positivo. Nesse sentido, levando em conta a distinção entre "com direito" (jure) no estado de natureza e "de direito" (de juri) no estado civil (cf. MS, AA 06:250), pode-se dizer que somente existe um vínculo analítico quando se fala de uma situação de direito. Esse ponto é reforçado em outro excerto:

Embora seu estado natural não devesse já por isso ser diretamente um estado de injustiça (injustus), o de enfrentar um ao outro apenas na simples proporção de sua força, ainda assim era um estado de ausência de direito (status justitia vacuus), no qual estando o direito em disputa (jus controversum), não se encontrara um juiz competente para proferir judicialmente a sentença, com base na qual então cada um pode compelir com violência o outro [den Anderen mit Gewalt antreiben darf] a entrar em um estado jurídico (MS, AA 06:312).

De modo específico, poder-se-ia dizer que no estado de natureza os direitos se vinculam apenas com a capacidade de violência recíproca (Gewalt), enquanto apenas no estado civil o direito é analiticamente vinculado à autorização para coação (Zwang). Entretanto, Kant não segue sempre essa diferença conceitual, sendo que em alguns momentos fala de um direito de coação (Zwang) também no estado de natureza (cf. MS, AA 06: 264; 307). De todo modo, em outro considerável número de vezes, ele utiliza para caracterizar o estado de natureza verbos como direito de obrigar ("ein Recht...zu nöthigen"- MS, AA 06:256), ou ainda, direito de manter afastado ("abzuhalten berechtig" - MS, AA 06:257). Isso é importante para a interpretação que estou propondo, a saber, que no estado de natureza, onde há apenas direitos provisórios e problemáticos, não há um vínculo analítico entre direito e coação. O que há, na verdade, é um vínculo entre direito e uso legítimo de "autodefesa" e proteção daquilo que se considera como seu em vista de uma condição jurídica posterior. É uma posse física "que tem a seu favor a presunção jurídica de fazer dela uma posse física pela reunião com a vontade de todos numa legislação pública e na espera vale comparativamente como posse jurídica" (MS, AA 06:257).

Nesse sentido, a violência (Gewalt) que existe no estado de natureza é comparativamente ou apenas provisoriamente considerada como legítima quando ela é usada diretamente para proteger o que é seu. Assim como não há direitos claramente estabelecidos e determinados, também não há coação em sentido próprio. No estado de natureza, os indivíduos e também os estados

tampouco são injustos uns com os outros ao se hostilizarem entre si, pois o que vale para um vale também reciprocamente para o outro, como que por um acordo: mas em geral são injustos em grau supremo por querer estar e permanecer num estado que não é um estado jurídico, i. é, no qual ninguém está seguro do seu contra violência (Gewalt) (MS, AA 06:307f.). 
Pode-se dizer assim que os direitos no estado de natureza são muito mais pretensões morais, as quais podem, devido a uma permissão específica da razão, estar vinculados ao uso da violência. Em outras palavras, no estado de natureza a violência pode ser problematicamente considerada como a coação quando ela se vincula ao direito por meio de uma lei permissiva da razão, a qual vale sob certos aspectos, mas não como um princípio e não analiticamente. ${ }^{13}$ Assim, é possível apresentar boas razões para permitir que os indivíduos utilizem de coação recíproca para constituírem um estado, mas não é possível apresentar boas razões para que a mesma permissão seja empregada no âmbito dos estados, no sentido de autorizá-los a utilizar de coação recíproca para entrar em uma federação de estados ou mesmo constituir uma república mundial. Se essa interpretação estiver correta, então não é a rejeição do uso de coação para formar uma federação de estados que deve ser justificada, mas, o reverso, a legitimidade de usar coação no âmbito individual para formar estados, em outras palavras, atribuir legitimidade a formação dos atuais estados surgidos pela violência.

O princípio de Kant de que "direito implica coação" permanece inalterado, pois ele se refere ao âmbito do direito em sua forma estrita, do direito positivado. Quando não há estruturas jurídicas que garantam a coação como meio de preservar o direito, trata-se então de direitos ainda em sentido impróprio. Trata-se de um direito provisório e incerto, o qual deve se tornar direito em sentido estrito, isto é, direito positivo.

Há ainda um outro tipo de direito que não implica coação, a saber, aquele vinculado ao dever do soberano ou do poder constituinte em reformar continuamente o estado para que ele se aproxime da forma republicana (cf. MS, AA 06: 340). Também aqui não se trata de um dever ético, pois é fundado no imperativo categórico do direito, porém também a ele não se vincula a uma autorização para coação.

Tendo isso em vista, proponho a seguinte divisão. Todos os deveres jurídicos, em distinção aos deveres éticos, permitem um outro fundamento de obrigação distinto da própria lei moral. Porém, nem todos os deveres jurídicos se constituem em deveres positivos, ou seja, deveres aos quais se pode vincular analiticamente coação. Poderíamos chamar esses deveres jurídicos, que aceitam outros móbeis além da própria lei moral, mas aos quais não se vincula analiticamente a coação, de deveres jurídicos pré-positivos (no caso dos direitos no estado de natureza) ${ }^{14}$ ou

13 Uma análise mais detalhada do conceito de lei permissiva da razão pode ser encontrada em Klein (2019a).

$14 \mathrm{Cf}$. "Ora, a vontade unilateral não pode servir de lei coercitiva para todos em vista de uma posse externa, portanto contingente, porque isso prejudicaria a liberdade segundo leis universais. Por conseguinte, somente uma vontade que obriga a cada um dos outros, portanto uma vontade universal (comum) coletiva e detentora do poder, é uma vontade que pode dar garantia a cada um. - Mas o estado sob uma legislação universal externa (i. é, pública) acompanhada de poder é o estado civil. Logo, somente pode haver um meu e teu externo no estado civil" (MS, AA 06: 256, 
suprapositivos (no caso do dever de reformar o estado). Em alguns casos é possível justificar a legitimidade de coação a esses deveres pré-positivos, mas isso não ocorre de modo analítico e sim sintético, ou seja, através de uma lei permissiva que deve avaliar o contexto.

Essa distinção entre direitos positivados, de um lado, e direitos pré-positivos e suprapositivos, de outro, poderia ser considerada como equivalente à distinção entre direito em geral e direito estrito. Segundo Kant:

[A]ssim como o direito em geral tem por objeto apenas o que é externo nas ações, assim o direito estrito, a saber, aquele em que não se mescla nada de ético, é aquele que não exige outros fundamentos de determinação do arbítrio a não ser os meramente externos, pois então ele é puro e sem mescla com qualquer proscrição de virtude. Portanto, só se pode chamar um direito estrito (estreito) o inteiramente externo (MS, AA 06: 232).

Essa relação analítica entre direito estrito e coação com o direito positivo é corroborada por dois aspectos. Primeiro, porque Kant afirma que os direitos estritos devem poder ser construídos em analogia com uma construção matemática (MS, AA 06:232s.). Ora, o cumprimento de tal exigência somente pode ser pensado com relação ao direito civil, pois somente então há uma estrutura jurídica que pode garantir isso. Por exemplo, estabelecendo objetivamente qual é a pena para determinado delito. Segundo, se analisarmos em detalhes o que se chamou acima de direitos pré-positivos e de suprapositivos, percebe-se que tais direitos sempre comportam uma motivação interna, ainda que não necessariamente ética, ou seja, determinada puramente pela lei moral. ${ }^{15}$ Tanto no caso dos direitos no estado de natureza, quanto no dever de realizar a reforma, há sempre uma referência à ideia de direito no sentido de fazer um uso tal que seja condizente com o princípio universal do direito. Entretanto, há uma indeterminabilidade deixada à interpretação do agente, a qual se vincula, por sua vez, a sua interpretação de como aplicar o princípio do direito em um caso específico. Por exemplo, o que seria tomar posse de uma terra no estado de natureza de tal modo que fosse condizente com a liberdade de todos os demais? E se não houver mais terras cultiváveis nas proporções reciprocamente adequadas? Esse é um ponto bastante relevante, pois nessa

pretensão está implícita ao mesmo tempo a admissão de estar reciprocamente obrigado a uma abstenção proporcional [gleichmäßigen Enthaltung] em relação a todos os outros em vista do seu externo, pois a obrigação procede aqui de uma regra universal da relação jurídica externa (MS, AA 06: 255, itálico acrescentado).

Mas retornando-se agora ao tópico desse artigo: quais as implicações dessa

itálico acrescentando).

15 Dörflinger (2016) considera esses deveres como sendo simplesmente deveres éticos, pois não comportam coação. Em sentido semelhante quanto ao caráter ético do cosmopolitismo, ver Brown (2009) e Perreau-Saussine (2010). 
discussão para a questão do dever de formação de uma federação dos povos e o posterior dever de criação de uma república mundial? O resultado é que esses deveres são deveres jurídicos em sentido geral e não deveres jurídicos estritos. Esses deveres são jurídicos e não éticos pois se fundam sobre o imperativo categórico do direito, se referem a ações externas e também aceitam outros fundamentos de determinação além da lei moral. Entretanto, esses deveres se referem ainda ao momento de construção de um direito estrito ou de sua constante reforma. Com essa interpretação, pode-se ao mesmo tempo sustentar que não há um direito de coação mútua entre os estados para formar uma federação de estados, sem que seja necessário abrir mão de uma tese absolutamente central ao direito kantiano a saber, de que direito em sentido estrito implica necessariamente em autorização para coação.

\section{Alguns princípios gerais da república mundial}

A passagem de uma federação dos estados para a república mundial é um dever jurídico geral ao qual não se vincula uma permissão para uso de coação recíproca. Entretanto, uma vez que essa passagem ocorra, os antigos estados abdicam da sua soberania à república de estados. Como esse processo não poderá ocorrer pela força, mas pelo esclarecimento da sua necessidade jurídica e após um longo desenvolvimento da cultura, essa república global precisará respeitar alguns princípios. Kant não os apresentou em detalhe, mas por uma extrapolação de outros elementos da sua filosofia político-jurídica pode-se apresentar algumas linhas gerais acerca deles.

Em primeiro lugar, sendo a república global um estado, caberia a ela a soberania quanto à decisão daquilo que the cabe e daquilo que ela pode deixar ao encargo dos membros da sua federação. Diferentemente da proposta de Höffe (2006, pp.193-203), que pensa em um estado ultramínimo em nível global, o qual possui e usufrui apenas de uma parte de soberania da qual os estados abrem mão, o conceito kantiano de república mundial possui o direito de regular tudo aquilo que interfere ilegitimamente nas esferas de liberdade dos indivíduos e dos estados em suas questões cosmopolitas. É a própria república mundial que decide o que entra ou não na sua esfera de decisão. Assim, não se trata apenas da interferência e mediação em caso de conflito entre os membros federados (como pensa Höffe), mas de regular tudo aquilo que pode interferir ilegitimamente na esfera da liberdade de outrem. Por exemplo: a emissão excessiva de gás carbônico por um membro da federação afeta indevidamente todos os demais; a criação de paraísos fiscais prejudica o controle da corrupção em todos os outros membros federados; a criação e manutenção de instituições de pesquisa para controle e prevenção de pandemias; 
ou ainda, o controle de exploração de mão de obra por multinacionais, tal como estabelecimento de um salário mínimo global ${ }^{16}$. Todas essas seriam questões que poderiam ser objeto de regulação jurídica por parte da república mundial, caso se concluísse que a sua regulação fosse necessária para garantir um sistema de igual liberdades.

Diferentemente de Habermas (2016, pp.188ss.), que defende uma constituição sem estado, ou da sugestão de Pogge (2009) de uma federação das nações dotada de múltiplos níveis de soberania partilhada, o modelo final de Kant é o de um estado global que surge e se mantém como república. Para Kant, essa é uma exigência do próprio conceito de direito estrito e da forma possível e adequada de preservar um igual sistema de liberdades. Em outras palavras, sem instituições legislativas, judiciárias e executivas globais, por conseguinte, sem a estrutura de um estado, permanecer-se-á no nível de um direito incerto e inseguro, um direito in fieri. De todo modo, a proposta de Kant de uma federação livre de estados seria equivalente à proposta de uma constituição sem estado de Habermas. Entretanto, para Kant, ainda que a criação dessa instituição intermediária seja um dever, essa federação deve ser entendida sempre como um momento de aprendizado e amadurecimento para a criação livre de uma república mundial. Esse aspecto é importante, pois indica uma direção aos esforços morais e jurídicos dessa federação, a qual deve sempre dar seguimento ao aprofundamento gradual dos princípios do direito em suas instituições, até que se tenha alcançado a maturidade para dar o passo de criação da república mundial.

Entretanto, ainda que a república mundial seja um estado e todo o seu direito público seja direito positivo, isso não significa que ela irá necessariamente interferir na esfera de liberdade dos estados federados e dos seus cidadãos. Mas a decisão acerca de quais esferas ela deixará indeterminadas ficaria a seu encargo, do contrário iria constantemente emergir uma nova disputa de autoridade e um regresso ao infinito. Nesse sentido, o modelo de soberania exigido pelo conceito de direito em Kant é o de uma soberania unitária e não uma soberania multidimensional aos moldes da filosofia medieval (que parece ser o modelo de Habermas) ou de uma soberania delegada ou cedida (como parece ser o modelo de Höffe). Ambos esses modelos caem no impasse que o próprio conceito de direito pretende evitar, a saber, numa situação em que não haja uma instância superior de decisão, ou seja, exatamente o problema jurídico do estado de natureza. A única forma de evitar isso é através de um modelo de soberania unitário e hierárquico que pratica autocontenção e que, por sua vez, delegue para as instâncias inferiores o direito para determinar as esferas

16 Sobre uma interpretação da filosofia kantiana com relação às questões morais de distribuição de riqueza ver Klein (2017b). 
mais específicas de direito. ${ }^{17}$ Por isso a república mundial é um estado mundial e os diversos povos comporiam, em um sentido jurídico global, um único povo. Nesse sentido, pode-se dizer que o modelo de Kant permite pensar que a república mundial seria um estado global mínimo, mas não porque os estados tivessem delegado apenas parte da sua autoridade, mas sim devido à maturidade político-moral alcançada pelas diversas repúblicas que comporiam a república das repúblicas. Nesse sentido, pode-se argumentar que a república mundial teria uma tendência natural de autocontenção jurídica.

A república mundial não deveria promover homogeneização da cultura, das línguas e religiões, mas isso também não significa que Kant defenda que os estados federados tenham de ser racial e etnicamente homogêneos exatamente para promover uma diversidade global. ${ }^{18} \mathrm{Em}$ todas as questões de bem, sejam aquelas que dizem respeito a um estado federado ou a indivíduos, isto é, em tudo aquilo que se relacione não ao conceito de justo, mas ao de felicidade, não haveria interferência da república mundial. Nesse caso, a república mundial deveria ser aquela instância que garante que cada um dos seus povos tenha o direito de buscar a sua felicidade da forma que thes aprouver, desde que isso não interfira na liberdade jurídica dos seus indivíduos e dos outros povos de fazer o mesmo. É fundamental notar que essa máxima universalidade legal não se contrapõe à máxima diversidade. Na verdade, a primeira é uma condição para a última. Uma analogia para esclarecer isso pode ser retirada do âmbito da natureza. As leis da física, da química e da biologia são as mesmas em todo o planeta Terra, nem por isso elas produziram uniformidade de espécies ou de ecossistemas. É exatamente porque há uma uniformidade dessas leis físicas, biológicas e químicas fundamentais que essa diversidade pôde surgir e se desenvolver em todo planeta, inclusive repovoando-o após extinções em massa.

Exatamente porque a república mundial deveria se preocupar apenas com aquilo que é de direito e não com aquilo que está relacionado com a felicidade, que os membros federados poderão ter culturas e estar em situações econômicas bastante

17 É importante notar que se o estado passa a ser o soberano frente aos indivíduos singulares, disso não se segue que o estado deva determinar cada aspecto da esfera de liberdade dos indivíduos. Em outras palavras, tudo aquilo sobre o que o estado se cala, fica à discricionariedade dos indivíduos. Assim, sob a premissa de que em tudo aquilo que não é proibido é permitido, segue-se que a soberania absoluta está no soberano que constitui o estado, o qual, por diversas razões pode deixar de intervir em outras esferas e permitir que nelas outros tipos de soberania subordinada ou derivada sejam estabelecidos. Por exemplo, o estado pode determinar que todas as crianças devam ir para a escola e que não devam ser agredidas, mas isso não significa que o estado deva determinar o restante da rotina da criança em casa, por exemplo, quantas e em que horário as refeições devem ser feitas. Desse modo, em tudo aquilo sobre o que o estado se cala, cabe aos pais exercerem sua autoridade, o que, de certo modo, implica uma certa noção de soberania derivada ou delegada. Essa perspectiva também se aplica à relação entre a república mundial e os estados federados.

18 MacCarthy (2002, p.251) confunde os níveis descritivos e normativos dos textos de Kant e acaba não considerando que o conceito de povo na filosofia política de Kant é eminentemente jurídico. 
distintas. Caberia à decisão de cada estado federado decidir o quanto e em que medida ele quer promover homogeneidade cultural ou não. A república mundial deve evitar o despotismo, mas também o paternalismo. ${ }^{19}$ A viva emulação da competição continuará a existir e a responsabilidade das decisões políticas dos estados federados deve ser assumida. Da mesma forma que a existência do estado não elimina todos os riscos, ${ }^{20}$ isso também não pode ser esperado de uma república mundial. A questão é que, assim como no estado os desacordos acerca dos direitos são decididos por instituições competentes e não mais pelo uso unilateral da força, também no âmbito entre estados e entre estados e indivíduos a violência e a força unilateral serão substituídas pela mediação jurídica dos conflitos. Em suma, a república mundial não envolve a representação idílica de uma harmonia e bondade natural entre os povos, mas uma forma de resolver os conflitos por vias institucionais competentes. Nesse sentido, a sociabilidade insociável continuaria a atuar, mas ela se torna disciplinada pelo direito de forma que ela não destrua os direitos alheios.

Por fim, apesar de Kant não desenvolver a ideia de uma república mundial em detalhes, pode-se dizer que ela deve assumir a forma de uma democracia representativa, ${ }^{21}$ sendo que todas as suas instituições deveriam ser constituídas segundo os princípios da liberdade, igualdade e independência ${ }^{22}$. Além disso, deveria assumir a forma de uma federação de estados, em que os estados de primeira ordem manteriam o direito de legislar em tudo aquilo que não vai de encontro com as leis da república mundial e naquilo sobre o que suas leis silenciam. 0 desenvolvimento dos detalhes da proposta extrapola o âmbito da apresentação dos princípios, que seria aquele da filosofia do direito e já adentraria o âmbito da pragmática e da experiência política.

19 Se um estado federado decide promover redistribuição de riqueza e investir em ciência e tecnologia, ou ainda, promover a diversidade de expressões culturais enquanto outro decide investir apenas na criação de commodities, e, ainda que não impeça, mas promova fortemente uma homogeneidade cultural, cada um deve ser responsabilizado e viver com as consequências. Por outro lado, a república mundial deve velar para que não haja interferência e constrangimento injusto entre os membros federados de modo que as esferas de liberdade sejam comprometidas, inclusive para que um estado tenha a possibilidade de escolher tomar outros rumos.

20 Cf. laG, AA 08: 26. Hobbes já havia apontando que a existência do direito não elimina os riscos e a violência: "Na verdade é impossível dar aos homens uma segurança completa contra quaisquer danos recíprocos, de modo que não corram o risco de ser feridos ou mortos injuriosamente; e portanto isto não vem ao âmbito de uma deliberação. Mas pode-se providenciar que não haja causa justa para o medo" (Hobbes 2002, p.103/VI,3).

21 Sobre a relação entre a filosofia política de Kant e o conceito de democracia representativa, ver Klein (2019b).

22 Para uma análise do conceito de república e sua relação com a moralidade na filosofia de Kant ver Klein (2016; 2014). 
Joel T. Klein

\section{Referências}

Axinn, S. (1989). Kant on World Government. In Funk G. \& Seebohm T. (ed.). Proceedings of the Sixth International Kant Congress (p. 245-249). Washington DC: University Press of America.

Baynes, K. (1997). Communitarian and Cosmopolitan Challenges to Kant's Conception of World Peace. In Bohman J. and Lutz-Bachmann (ed.). Perpetual Peace: Essays on Kant's Cosmopolitan Ideal (pp. 219-234). Cambridge, MA: MIT Press.

Bernstein, A. (2014). The Right of States, the Rule of Law, and Coercion: Reflections on Pauline Kleingeld's Kant and Cosmopolitanism. Kantian Review, 19(2), 233249. DOI: https://doi.org/10.1017/S136941541400003X

Bosbach, F. (1998). The European debate on Universal Monarchy. In Armitage, D. (ed.). Theories of Empire, 1450-1800 (pp. 81-98). Ashgate.

Brown, G. W. (2009). Grounding Cosmopolitanism: From Kant to the Idea of a Cosmopolitan Constitution. Edinburgh: University Press.

Byrd, S., Hruschka, J. (2008). From the state of nature to the juridical state of states. Law and Philosophy, 27(6), 599-641. DOI: https://doi.org/10.1007/s10982-008-9029-7

Byrd, S., Hruschka, J. (2010). Kant's Doctrine of Right: A Commentary. Cambridge: Cambridge University Press.

Carson, T. (1988). Perpetual peace: What Kant should have said. Social Theory and Practice, 14, (2), 173-214.

Dörflinger, B. (2016). Juridical and Ethical Aspects of the Idea of Peace in Kant. Studia Kantiana, 14(20), 05-19.

Habermas, J. (2016). A constitucionalização do direito internacional ainda tem uma chance? In Habermas, J. O ocidente dividido (pp.161-270). São Paulo: Unesp.

Hobbes, T. (2002). Do cidadão. Tradução de Renato Janine Riberio. São Paulo: Martins Fontes.

Höffe, O. (2006). Kant's Cosmopolitan Theory of Law and Peace. Cambridge: Cambridge University Press.

Kant, I. (1980). Crítica da razão pura. Tradução de Valerio Rohden e Udo Baldur Moosburger. São Paulo: Abril Cultural.

Kant, I. (1990ss.). Gesammelte Schriften. hrsg: Bd. 1-22 Preussische Akademie der Wissenschaften, Bd. 23 Deutsche Akademie der Wissenschaften zu Berlin, ab Bd. 24 Akademie der Wissenschaften zu göttingen. Berlin: [s. n.].

Kant, I. (2002). Crítica da faculdade do juízo. Traducão de Valerio Rohden e António Marques. 2. ed. Rio de janeiro: Forense Universitária.

Kant, I. (2004). A paz perpétua e outros opúsculos. Tradução de Artur Morão. Lisboa: Edições 70.

Kant, I. (2005). A metafísica dos costumes. Tradução de José Lamego. Lisboa: Calouste Gulbenkian.

Kant, I. (2009). Fundamentação da metafísica dos costumes. Tradução, introdução e notas de Guido Antônio de Almeida. São Paulo: Discurso Editorial. 
Kant, I. (2014). Princípios metafísicos da doutrina do direito. Tradução e introdução de Joãosinho Beckenkamp. São Paulo: Martins Fontes.

Klein, J. T. (2014). Arelação entre ética e direito na filosofia política de Kant. Manuscrito (UNICAMP), 37, 161-210. DOI: http://dx.doi.org/10.1590/S0100-60452014000100005

Klein, J. T. (2016). O Estado republicano democrático e o ensino público da moral segundo Kant. Discurso - Departamento de Filosofia da USP, 46, 85-122. DOI: https://doi.org/10.11606/issn.2318-8863.disc..2016.123672

Klein, J. T. (2017a) Prudência e moral na filosofia política de Kant. Estudos Kantianos, 5, 159-178. DOI: https://doi.org/10.36311/2318-0501.2017.v5n1.12.p159

Klein, J. T. (2017b) Considerações críticas acerca do libertarianismo de Nozick à luz da filosofia moral kantiana. Revista latinoamericana de filosofía, 43, 65-104.

Klein, J. T. (2019a). Considerações sobre a justificação de Kant acerca da propriedade privada. Veritas (Porto Alegre), 64(2), e32715. DOI: https://doi.org/10.15448/1984-6746.2019.2.32715

Klein, J. T. (2019b). Kant e o Valor Moral da Democracia Representativa. Revista portuguesa de filosofia, 75(1), 667-694. DOI: https://doi.org/10.17990/RPF/2019_75_1_0667

Klein, J. T. (2020). O Cosmopolitismo Jurídico de Kant. Ethic@ (UFSC), 19(2), 209249. DOI: https://doi.org/10.5007/1677-2954.2020v19n2p209

Kleingeld, P. (2004). Approaching Perpetual Peace: Kant's defense of a league of states and his ideal of a world federation. Journal of European Philosophy, 12, 304-25. DOI: https://doi.org/10.1111/j.0966-8373.2004.00212.x

Kleingeld, P. (2012). Kant and Cosmopolitanism: The Philosophical Ideal of World Citizenship. Cambridge: Cambridge University Press.

Kleingeld, P. (2014). Patriotism, peace and poverty: reply to Bernstein and Varden. Kantian Review, 19(2), 267-284. DOI: https://doi.org/10.1017/S1369415414000053

Mccarthy, T. (2002). On Reconciling Cosmopolitan Unity and National Diversity. In C. P. Cronin \& P. DeGreiff (ed.). Global Justice and Transnational Transitional Politics (pp.235-274). Cambridge: MIT Press.

Merkel, R. (1996) Lauter leidige Tröster. Kants Fridenschrift und die Idee eines Völkerstrafgerichtshofs. In Merkel, R., Wittmann, R. (Hrsg.). Zum ewigen Frieden: Grundlagen, Aktualität und Ausichten einer Ideen von Immanuel Kant (pp. 309350). Frankfurt am Main: Suhrkamp.

Mikalsen, K. K. (2011). In defense of Kant's league of states. Law and Philosophy, 30, 291-317. DOI: https://doi.org/10.1007/s10982-011-9094-1

Nussbaum, M. (1997). Kant and Cosmopolitanism. In Bohman J., Lutz-Bachmann (ed.). Perpetual Peace: Essays on Kant's Cosmopolitan Ideal (pp. 25-58). Cambridge, MA: MIT Press.

O'Neill, O. (2002). Instituting Principles: Between Duty and Action. In Timmons M. (ed.). Kant's 'Metaphysics of Morals'. Interpretative Essays (pp. 331-347). Oxford: Oxford University Press.

Perreau-Saussine, A. (2010). Immanuel Kant on international law. In Perreau-Saussine, A.; Tasioulas J. (ed.). The philosophy of international law (pp. 53-78). Oxford: Oxford University Press. 
Joel T. Klein

Pogge, T. (2009). Kant's Vision of a Just World Order. In Hill T. E. (ed.). The Blackwell Guide to Kant's Ethics (pp. 196-208). Oxford: Wiley-Blackwell.

Raponi, S. (2008). What's Wrong with a World State? Kant's Conception of State Sovereignty and His Proposal for a Voluntary Federation. In Rohden, V., Terra, R. R., Almeida, G. A. de \& Ruffing, M. (Hrsg.). Recht und Frieden in der Philosophie Kants. Akten des X. Internationalen Kant-Kongresses (pp. 665-676). Bd. 4. Sektionen V - VII. Berlin: Walter de Gruyter.

Timmerman, J. (2013). Kantian Dilemmas? Moral Conflict in Kant's Ethical Theory. Archiv für Geschichte der Philosophie, 95(1), 36-64. DOI: https://doi.org/10.1515/agph-2013-0002 